\title{
DOCÊNCIA E CONHECIMENTO DE SI: ESPAÇO FORMATIVO EM CLASSES MULTISSERIADAS
}

\author{
TEACHING AND KNOWLEDGE OF SELF: FORMATIVE SPACE IN MULTIGRADE \\ CLASSES
}

\author{
Charles Maycon de Almeida Mota \\ Doutorando em Educação e Contemporaneidade \\ Universidade do Estado da Bahia - UNEB \\ Secretaria Municipal de Educação de Várzea do Poço/BA \\ Várzea do Poço, Bahia - Brasil \\ charlesmaycon22@hotmail.com \\ iD Fabricio Oliveira da Silva \\ Doutor e Pós-Doutor em Educação e Contemporaneidade \\ Universidade Estadual de Feira de Santana - UEFS \\ Feira de Santana, Bahia - Brasil \\ faolis@uol.com.br \\ Jane Adriana Vasconcelos Pacheco Rios \\ Doutora e Pós-Doutora em Educação \\ Universidade do Estado da Bahia - UNEB \\ Salvador, Bahia - Brasil \\ jhanrios1@yahoo.com.br
}

Resumo: O presente estudo trata da formação docente a partir do conhecimento de si, enquanto espaço de formação e de atuação profissional em classes multisseriadas. Objetivou-se compreender como os professores lidam e refletem sobre as diferenças em sala de aula. Trata-se de uma pesquisa-formação desenvolvida com três professores que vivem e convivem em contextos rurais em um município do interior da Bahia. Esta pesquisa é fundamentada no método (auto)biográfico. Como dispositivo de recolha de informações, utilizaram-se as narrativas. Percebeu-se que o conhecimento de si, como espaço de formação, desencadeia uma auto, eco e coformação, como princípios formativos que transversalizam o fazer docente em contextos de diversidade.

Palavras-chave: classes multissseriadas; conhecimento de si; formação docente; ruralidades contemporâneas.

\begin{abstract}
The present study deals with teacher formation based on knowledge of self, as a space for formation and professional performance in multigrade classes. The objective was to understand how teachers deal with and reflect about differences in the classroom. It is a research-formation developed with three teachers who live in rural contexts in a municipality in the interior of Bahia. This research is based on the (auto) biographical method. The narratives were used as a device for collecting information. It was perceived that knowledge of self, as a formation space, triggers a self, echo and co-formation as formative principles that transversalize teaching in contexts of diversity.
\end{abstract}

Keywords: multigrade classes; knowledge of self; teacher formation; contemporary ruralities.

Para citar - (ABNT NBR 6023:2018)

MOTA, Charles Maycon de Almeida; SILVA, Fabricio Oliveira da; RIOS, Jane Adriana Vasconcelos Pacheco. Docência e conhecimento de si: espaço formativo em classes multisseriadas. Eccos - Revista Científica, São Paulo, n. 57, p. 1-18, e14541, abr./jun. 2021. Disponível em: https://doi.org/10.5585/eccos.n57.14541. 


\section{Introdução}

Os pressupostos de formação evidenciados neste trabalho acentuam-se nos princípios da pesquisa-formação que é inspirada na teoria tripolar de Pineau (2014), concebendo o Conhecimento de si como um espaço de formação que evidencia a prática desenvolvida na docência como um fazer que se reconfigura a partir da dinâmica que se efetiva através das relações que se dão no cotidiano da escola com destaque para as Séries Iniciais do Ensino fundamental em Classes Multisseriadas.

Com isso, compreendemos que uma formação fundamentada numa concepção que toma o conhecimento de si como espaço de formação e, também, o coloca como elemento constituinte do processo de formação que se revela na heteroformação, autoformação e ecoformação a partir das narrativas (auto)biográficas se coloca como um procedimento formativo construído entre e com os professores num movimento retroalimentar de açãoreflexão-formação correlacionado aos princípios da autonomia, reciprocidade, auto/eco/coformação que configura ações de uma tessitura artesanal, entendida neste estudo como formação.

No caso específico do Ensino Fundamental, pensamos o Conhecimento de si na relação com as práticas educativas que revelam diferenças que atravessam o cotidiano das Classes multisseriadas em escolas da roça a partir do processo de (auto)formação docente. Ou seja, entendemos que o trabalho com as diferenças na escola mobiliza um posicionamento político identitário que possibilita outros modos de significar a docência na escola básica, revelando diferentes projetos de existência dos professores. Nas Classes multisseriadas, a formação esteve sempre à deriva decorrente, entre outros aspectos, do lugar residual em que a multisseriação ocupou nas políticas públicas educacionais. Na contramão destes processos, docentes vêm construindo pedagogias singulares, ancoradas em modos de ser, de viver e de produzir reflexões sobre a docência, que refletem o cotidiano vivido nas comunidades rurais, bem como trazem à baila as reflexões que se produzem no seio da vivência e produção de experiências tecidas no fazer docente. Por este entendimento, o presente trabalho revela os projetos de si dos docentes ao trazerem práticas cotidianas desenvolvidas nas Classes multisseriadas e, consequentemente, na construção da profissão nesse tempo-espaço formativo.

Diante deste contexto, o presente estudo buscou compreender como os professores que atuam no Ensino Fundamental em Classes multisseriadas lidam e refletem sobre as diferenças em sala de aula? Quais elementos do Conhecimento de si constituem-se enquanto espaço de formação para e com a docência na roça? Desse modo, o objetivo dessa investigação teve como 
centralidade compreender o Conhecimento de si como um espaço de formação que evidencia as práticas desenvolvida na docência em classes multisseriadas como um fazer que se reconfigura a partir da dinâmica que se efetiva através das relações que se dão no cotidiano da escola.

Neste sentido, este texto organiza-se em três seções, nos quais procuramos apresentar a trajetória da pesquisa a partir da Pesquisa-formação, o Conhecimento de si como espaço formativo e, por fim, as dimensões do Conhecimento de si no processo de formação dos docentes na relação com a diferença no trabalho com as Classes multisseriadas.

\section{Percurso metodológico}

Para o desenvolvimento deste estudo, utilizamos a Pesquisa-formação por trazer a possiblidade de (re)flexionar a respeito do conhecimento de si como espaço de formação e compreensão das diferenças neste contexto. Esclarecemos, como muitos pesquisadores o fazem como o caso de André (2002), que a pesquisa-formação não constitui um tipo específico de metodologia de pesquisa, mas uma gênese desta que se fundamenta no poder que a própria pesquisa tem de produzir formação em quem se envolve com ela.

Partilhando de tal compreensão, concebemos que a presente pesquisa se tipifica, também, enquanto pesquisa-formação por mobilizar os colaboradores a refletirem sobre si e sobre seus percursos, analisando na relação consigo mesmo, com o ambiente da multisseriação, e com os outros, formas de construir e tomar consciência dos sentidos que imprime para aquilo que faz e como faz na escola. É o conhecimento de si como processo relevante da produção e elucidação de como as concepções que se produzem sobre as diferenças na escola se singularizam nos modos de ser e de viver as práticas educativas.

Essa investigação é desenvolvida com a utilização do método (auto)biográfico que compreende o movimento da pesquisa-formação realizada com professores de classes multisseriadas. Para Dominicé (2014, p. 81): “(...) o estudo biográfico, apela à reflexão e resulta de uma tomada de consciência, dá origem a um material de investigação que é já o resultado de uma análise. A diversidade dos dados deve assim ser recebida como uma pluralidade de compreensão biográfica".

A pesquisa-formação se colocou como um espaço de produção de dados que nos trouxe condições de narrar a vida e os processos da docência no Ensino fundamental em classes multisseriadas, fortalecendo o movimento de reflexividade formativa de cada envolvido. Neste contexto metodológico, o método (auto)biográfico foi uma potência no desenvolvimento da 
pesquisa que realizamos, pela possibilidade de permitir aos sujeitos envolvidos narrarem sob seus pontos de vistas e escolhas, fatos e informações relevantes no percurso profissional da docência em classes multisseriadas. Cabe ressaltar que utilizamos como instrumento de pesquisa a entrevista narrativa por entender que esta, também, constituiu-se como o dispositivo singular da narratividade, caracterizando-se como um elemento de formação neste contexto da pesquisa-formação.

A pesquisa configurou-se numa proposta de formação que foi realizada em nove encontros, totalizando numa carga horária de trinta horas. Em cada encontro, desenvolveramse oficinas formativas, as quais constituíram o cenário de pesquisa e produção de dados, como também, nos trouxe discussões fecundas e proposições de temáticas referentes às necessidades dos colaboradores da pesquisa. As entrevistas narrativas foram produzidas no âmbito das reflexões e discussões produzidas nas oficinas. Assim, houve o momento de narratividade de cada sujeito colaborador, fazendo fluir sua história de vida, formação e desenvolvimento profissional no âmbito da docência em classes multisseriadas. As entrevistas foram gravadas e, consequentemente, transcritas, lidas e autorizadas por cada professor colaborador deste estudo.

Neste texto, apresentaremos as experiências (auto)formativas de três professorescolaboradores ${ }^{1}$ que atuam em classes multisseriadas, em um município do interior do estado da Bahia, cujo perfil biográfico apresentado abaixo revela algumas características iniciais que (de)marcam elementos do percurso de vida e formação.

\begin{tabular}{|c|c|c|c|c|c|}
\hline Colaborador & Sexo & Idade & Formação & $\begin{array}{c}\text { Carga } \\
\text { horária }\end{array}$ & $\begin{array}{l}\text { Tempo de } \\
\text { docência }\end{array}$ \\
\hline Clóvis & M & 48 anos & $\begin{array}{l}\text { Graduado em } \\
\text { Letras com } \\
\text { Espanhol e em } \\
\text { Pedagogia. } \\
\text { Especialista em } \\
\text { Metodologia da } \\
\text { Língua Portuguesa }\end{array}$ & $20 \mathrm{~h}$ & 29 anos \\
\hline Edson & M & 49 anos & $\begin{array}{l}\text { Graduado em } \\
\text { Letras com } \\
\text { Espanhol e em } \\
\text { Pedagogia. }\end{array}$ & $20 \mathrm{~h}$ & 29 anos \\
\hline Ester & $\mathrm{F}$ & 49 anos & $\begin{array}{l}\text { Graduada em } \\
\text { Pedagogia. }\end{array}$ & $20 \mathrm{~h}$ & 33 anos \\
\hline
\end{tabular}

Fonte: Diário de campo da pesquisa (2016)

\footnotetext{
${ }^{1}$ Os professores-colaboradores da pesquisa possuem nomes fictícios, em atendimento ao Comitê de Ética em Pesquisa da Universidade do Estado da Bahia -
} $\mathrm{UNEB}$, ao qual a pesquisa realizada foi submetida e aprovada através do Parecer $\mathrm{n}^{\circ} 1.231 .903$ 
Essa proposta foi intitulada de Enveredar para si e teve forte inspiração nos Ateliês biográficos de Delory-Momberger (2006), em que a biografia educativa se encontra atrelada a um objeto de investigação - o conhecimento de si - e a um contexto educativo - as oficinas formativas. Esse aspecto metodológico da biografia educativa faz referência a um movimento de formação contínua, mas exigindo momentos específicos, que favoreçam a (auto)reflexão do docente sobre o seu percurso de vida e formação, com vistas à construção de uma formação que focalize os processos de interiorização e exteriorização em busca da consciência de si.

\section{Conhecimento de si: espaço formativo na escola da roça}

O conhecimento de si apresentado neste trabalho está concentrado nas narrativas que possibilitam ao sujeito da/na formação rememorar momentos vividos no decurso de sua vida, que constituíram e constituem suas experiências, sendo estas evidenciadas enquanto "experiências formadoras, as quais são perspectivadas a partir daquilo que cada um viveu e vive, das simbolizações e subjetivações construídas ao longo da vida" (Souza, 2006, p. 95).

Entendendo que conhecer-se a si mesmo é mobilizar os elementos que possam contribuir ao processo de interioridade que o sujeito precisa desenvolver, evocando um passado que é anunciado, no presente, como perspectiva de futuro, expondo e denunciando os fatos e momentos eleitos como importantes e necessários quando são invocados. Como podemos contemplar na narrativa de Edson, o conhecimento de si vai sendo desvelado como um elemento de compreensão de seu percurso de vida-formação-profissão e reflexão a respeito do desenvolvimento de sua prática docente.

(...) A primeira experiência como professor, (...) foi tirando as férias de minha irmã que trabalhava como educadora, pois ela tinha ganhado o primeiro bebê. (...) Fiz um teste como professor e fui contemplado. A partir do dia que comecei a trabalhar como professor, graças ao nosso bom Deus eu me senti realizado, passei a ganhar a metade do saláriomínimo. Depois vieram os poréns. Trabalhava e ficava vários meses sem receber. Mas com tudo isso que aconteceu, eu não desisti, continuei, superei e estou trabalhando até os dias atuais. Compreendendo a importância que tem o educador na formação dessas crianças, estou a cada dia buscando inovar a minha prática pedagógica. (Edson. Entrevista Narrativa, 2016)

A situacionalidade que revela a narrativa do professor Edson, traz para a cena o modo como vive a entrada na profissão. A substituição à irmã é a primeira entrada na profissão, após um teste para a docência. Isso já indica a existência de uma ideia de que, para ser docente há um saber específico, um modo de atuar que precisa ser validado por um tipo de testagem. No entanto, o conhecimento de si emerge como princípio fundante do processo, pois aponta para 
uma compreensão do papel educativo que tem o professor para atuar na docência. Isso está para além do teste e da oportunidade de iniciar o exercício docente, a quem o professor atribui o feito a vontade divina, a uma dádiva, que é a permissão de Deus para isso.

Ao estar na profissão, a reflexão sobre si e como atuar na produção de práticas educativas inovadoras é o elemento mobilizador que faz com que Edson logre condições de aprender com as próprias crianças para pensar sobre o que seria inovador, com a tessitura da realidade escolar em que se encontra, para ressignificar suas práticas no ambiente, e por fim consigo mesmo para analisar o que seria e o que não seria inovador a fim de construir para si a consciência na necessidade de produção de mudanças, de transformação das práticas que desenvolve, tornando-as, para si e para as crianças, de natureza inovadora.

Este procedimento docente exige uma reflexão sobre si, rememorando acontecimentos, tomando consciência daquilo que foi elemento basilar do percurso de formação/experiência na profissão docente. Neste trabalho, conhecer o outro retoma o lugar da escuta sensível e da valorização das histórias de vida dos sujeitos envolvidos nas escolas rurais, como um fator fundante e formativo da docência, no qual os princípios de formação do sujeito que narra sobre si e para si estejam direcionados para a reciprocidade, criando-se maneiras de coexistência entre estes sujeitos e suas localidades.

Neste caso, o conhecimento de si se coloca como uma perspectiva de outros espaços de formação na escola rural, por sinalizar para as diversas veredas que poderão nos conduzir à construção de uma educação que valorize os sujeitos em suas condições de existência, compreendendo que o seu ser-fazer engloba uma multidimensionalidade responsável pelo que Josso (2008) considera como projeção de si, provocando uma reorientação do sujeito, que se (re)posiciona diante de suas perspectivas de futuro, estas que são, por sua vez, reavaliadas, revistas e repensadas, como parte de sua exterioridade enquanto ser-sujeito.

O professor Clóvis ao refletir sobre sua posição social diante da visão dos pais, revela um modo próprio do conhecimento de si e de sua função social que vai além do que os pais atribuem a ele frente a missão de ensinar aos filhos. Instaura-se uma perspectiva reveladora do conhecimento de si que eclode no processo de retomada das memórias de nossa trajetória de vida-formação-profissão, como uma maneira de entender como a produção de sentidos na docência em classes multisseriadas. Refletir sobre si e sobre seu papel enquanto docente no contexto das escolas multisseriadas, faz com que surjam modos próprios de entender-se na docência pela relação com o outro e de confiança que lhe é depositada. 
Isso gera uma condição reflexiva, por meio da qual os professores vejam-se em condições de (re)significarem seus fazeres e lançarem mão de princípios formativos como açãoreflexão-formação, autonomia, reciprocidade, auto/eco/coformação e diversidade como modos de pensar a formação atrelada a suas trajetórias de vida-profissão-formação.

A comunidade aos poucos foi se desenvolvendo e o número de crianças crescia. Os pais preocupados com a educação de seus filhos convocaram o prefeito do município e cobrou dele uma escola para que todas as crianças pudessem estudar. Por ser sempre uma pessoa responsável e por me dedicar como líder da comunidade, os pais sugeriram-me como uma pessoa capaz de ministrar aulas para seus filhos. (Clóvis. Entrevista narrativa, 2016)

Nesse sentido, o conhecimento de si nos oferece condições de desenvolvimento de uma formação docente baseada em perspectivas que valorizam e consideram, como elemento importante da construção de um fazer docente condizente com o protagonismo dos que ensinam e dos que aprendem, a experiência daqueles que se encontram envolvidos no cotidiano das escolas rurais. Assim, estar na condição docente tem um atributivo social demarcado pelas relações que se estabelecem com os estudantes e com os pais, de quem o professor recebe a ideia de representação de que tem plenas condições de educar e de desenvolver um papel social que modifique as realidades dos estudantes.

Trata-se de um espaço de formação na escola rural que é prospectado a partir do conhecimento de si e do outro, colocando-se, então, como uma condição que emerge da vontade do docente em se predispor a conhecer a si mesmo como pressuposto para o conhecimento do outro, focado em um processo de unicidade e alteridade, pelo qual se coloca, a priori, a relação do docente consigo mesmo e, a posteriori, a relação com o outro.

Nesse caso, Josso (2010) reitera que esse é um momento em que o docente toma consciência de uma consciência que deve ter sobre si mesmo, ressurgindo do coletivo, cultural e biológico, e buscando sua individuação a partir da unicidade. Isso se dá a partir de um processo que envolve revisitar pontos significantes de nossas vidas e, mais especificamente, da nossa experiência como docente.

O coletivo se evidencia na narrativa de Clóvis quando ele situa a sua condição de docente pelo aspecto colaborativo e relacional com os pais, com aquilo que estes expressam sobre a condição do professor exercer sua função, bem como com as crianças, com quem exerce reflexão sobre pontos significantes das vidas destas e da missão de educá-las no contexto da cotidianidade da multisseriação. Isso tem a ver com as formas de consciência de si e de seu papel que são mobilizados no contexto da pesquisa-formação, quando o professor ao narrar 
evoca a si e para si os sentidos que sua atuação enquanto docente produz no ato reflexivo que Clóvis faz de si e de sua condição de professor.

Quando colocamos em evidência o conhecimento de si como uma premissa, em que o docente tem a oportunidade de refletir a respeito de sua experiência e formação, o fazemos ancorados nos fundamentos dos estudos de Josso (2010). Estes apresentam o conhecimento de si como um pressuposto do engajamento docente no seu próprio processo de formação, perpassando pelas questões de autonomização, individuação e interioridade, e compreendem, assim, quais são os elementos fundantes de sua prática docente, ao refletirem sobre sua intencionalidade.

O movimento de conhecer-se a si mesmo está fundado na busca que o sujeito faz de sua individuação, para entender os processos de subjetivação e sua relação com os grupos em que está inserido. Complementando tal pensamento, Souza (2006, p. 138) menciona que "o sujeito desloca-se numa análise entre o papel vivido de ator e autor de suas próprias experiências, sem que haja uma mediação externa de outros”.

Esse sujeito passa a ser o responsável pela mobilização dos elementos próprios e intrínsecos a suas necessidades formativas, uma vez que se coloca numa condição de reflexão e autorreflexão, a partir da rememoração do seu percurso de vida, pessoal e profissional, escrevendo e se inscrevendo em suas narrativas, sem a intervenção de outrem, pois o conhecimento de si somente pode acontecer a partir do momento em que o próprio sujeito toma consciência da consciência de si (Josso, 2010), e isso só acontece no processo de individuação desse sujeito.

Diante disso, o conhecimento de si se evidencia como espaço potente de formação das trajetórias de vida e de inserção e atuação profissional, pois é do lugar de quem reflete sobre sua ação docente a partir do movimento de narratividade que cada professor se permitiu fazer para pensar nas questões da diferença em classes multisseriadas.

\section{O conhecimento de si como princípio formativo e de atuação na docência em classes multisseriadas}

Narrar sobre si, revelando seu percurso formativo e de atuação na docência de escolas multisseriadas figura como um princípio formativo de que o professor lança mão para entender e ressignificar a compreensão que produz dos seus modos de ser e de produzir experiências no seu fazer docente. A produção de uma narrativa (auto)biográfica evoca as subjetividades do sujeito que se fazem e refazem no discurso de si e sobre si. Nesta direção, a perspectiva 
(auto)biográfica situa-se no campo da pesquisa qualitativa como uma possibilidade de desenvolvimento de pesquisa-formação, uma vez que para narrar autobiograficamente o sujeito tece reflexões que se produzem no momento da feitura da própria narrativa. Isso indica que ao narrar o professor não tem em si a clareza e as informações que serão narradas. Tais informações são produzidas no/pelo contexto das atribuições de sentido que se efetivam quando as escolhas sobre o que e como narrar se produzem.

Sendo assim, a escola se coloca como um espaço formativo, reconhecida socialmente pelo papel que desenvolve nas comunidades rurais, pode ser (re)pensada, a partir das condições do meio em que se encontra inserida e das maneiras de vida que têm aqueles que a frequentam, impulsionando um movimento que seja coerente com as necessidades e anseios desses locais. Com isso, Amiguinho (2008) ressalta que a escola passa a engendrar o caráter político e social destas comunidades, que passam a ser consideradas como portadoras de futuro.

Quando tomamos a escola da roça, estamos concebendo as ruralidades contemporâneas, com uma centralidade nos aspectos constituintes dos processos de subjetividade existentes nos espaços rurais, em que são enaltecidas as identidades e diferenças como um pressuposto da demarcação de um lugar no mundo. A escola, como propagadora do saber, poderá se apropriar de tais pressupostos para promover o encontro das culturas em seu espaço.

A trajetória de vida-escolarização-profissão de professores da roça é marcada pelo movimento impulsionado pela importância que cada família atribui à educação como um processo de transformação social e cultural em suas comunidades. As pessoas que vivem e convivem em espaços rurais concebem a escola de sua comunidade como espaço de possibilidades e portador de futuro.

Por isso, a docência neste contexto é atravessada pela compreensão de que é pelo esforço e pela vontade de saber que os sujeitos de comunidades rurais entendem suas situações de vida e projetos de futuro. Como podemos perceber nas narrativas desses professores, a condição para o acesso à escola se colocava pelo lugar de dificuldades para percorrer longas distâncias e dividir seu tempo entre o trabalho e o estudo.

Por ser filho de agricultor e agricultora, ingressei na escola a partir dos sete anos de idade numa escola do campo. Foi daí que começou a minha trajetória como educando. Eu caminhava aproximadamente 9 a 10 quilometros todos os dias para chegar até a escola, mas eu tinha muito interesse de aprender que tudo isso acontecia de forma prazerosa. (Edson. Entrevista narrativa, 2016) 
Tive que parar por ser muito difícil ter que vim estudar em Várzea do Poço. Depois de muito tempo, em 1984, eu vinha estudar em Nova Esperança a pé. Eu e Isaura, na volta, as vezes tinha a companhia de um senhor por nome Doro, que trabalhava de guarda, $e$ outras (vezes) era só nós duas enfrentando muitas dificuldades para concluir a 8 a série. Mais uma vez parei de estudar. Momentos que marcaram muito a minha vida. (Ester. Entrevista narrativa, 2016)

Aos dez anos de idade dei início a minha carreira estudantil, passando por um processo de alfabetização, frequentei uma escolinha distante de onde morava, senti que a sorte poderia estar chegando para me acompanhar. (Clóvis. Entrevista narrativa, 2016)

As narrativas dos professores da roça revelam como a persistência que tinham para frequentar a escola e, isso, os fazem refletir sobre quais as condições das escolas em que, atualmente, desenvolvem a docência e como compreendem a situação de vida de seus alunos. O conhecimento de si emerge como ponto de reflexão das dificuldades que os professores enfrentaram nas trajetórias de escolarização. Ganham sentidos as dificuldades vivenciadas, sobretudo pela distância reveladas nas travessias de ida e vinda à escola. Assim, esse conhecimento experiencial, vivido por cada um ressignifica o modo de ser e de viver a docência nas classes multisseriadas, facultando aos professores uma condição de perceber, entender e atender os estudantes em suas dificuldades.

Além da multisseriação, a ida e vinda da escola na comunidade passa a ser um ponto de reflexão que os professores adotam para ver-se na docência a partir de experiências que tiveram na comunidade. Esse é o conhecimento de si que emerge da singularidade e da subjetividade vivida por cada um, e que, por esta razão, figura-se nas narrativas em seus aspectos formativos, que dão o tom à docência que cada um desenvolve na comunidade, fato que nos permite perceber como os aspectos ecoformativos, um dos que configuram a docência nas escolas multisseriadas, são contemplados nas histórias de vida narrada por cada professor.

Contar de si, apresentando como os processos de vida-escolarização acontecem nos contextos rurais traz à tona elementos necessários para o fazer docente na roça possibilitando a esses professores uma formação com visibilidade para uma lógica outra que colabore com o reposicionamento da docência em contextos rurais pelo lugar da valorização das condições estruturais e estruturantes das escolas nestes espaços, sem perder de vista a importância da função que esta instituição tem para as comunidades rurais.

Em meio a todos esses dilemas, desafios e perspectivas, que se apresentam quando nos referimos às ruralidades e à escola da roça, encontramos a docência, que precisa ser concebida e trabalhada a partir destes novos olhares e sentidos do rural. A docência nas escolas rurais ocorre a partir da contemplação inicial de que os modos de vida na roça não se firmam somente 
nas atividades agrícolas. Carneiro (1998, p. 56) aponta para o fenômeno da pluriatividade, que "adquire novas dimensões no campo brasileiro, chamando a nossa atenção para a possibilidade de novas formas de organização da produção virem a se desenvolver no campo ou de antigas práticas assumirem novos significados". Tendo esse redimensionamento já presente nas estruturas sociais, econômicas e culturais, torna-se possível o desenvolvimento de práticas docentes multirreferenciais, que coloquem a escola no seu verdadeiro lugar na comunidade.

No fazer docente em classes multisseriadas, a relação da docência com a forma de lidar com as diferenças estrutura-se, geralmente, de um processo histórico que tem raízes nas questões sociais e políticas em torno da constituição do próprio sujeito e do trabalho que ele desenvolve na escola.

Neste sentido, a diversidade foi compreendida como uma dimensão construída a partir de um processo histórico, social e político, resultante das interações entre os sujeitos que reivindicaram seus espaços através da força imanente de grupos constituídos pela identificação resultante das diferenças e subjetividades que os coletivizaram, possibilitando aos espaços escolares uma tessitura construída de encontros e desencontros, tensões e negociações, que dão formas, sentidos e significados às relações humanas.

Conforme a narrativa de Ester, colaboradora da pesquisa, podemos notar situações de enfrentamento, negociação e acolhimento que estão presentes em suas intervenções quando percebe o conflito entre seus alunos.

No caso do menino (...) que chegava na escola todo sujo de graxa e ele era chamado de come graxa. Apelidaram ele desse jeito e ele se sentia mal, (...). Conversei com ele para saber porque ele chagava melado na escola, ele disse que era porque ajudava o pai a consertar os carros. Chamei ele pra fora da sala e conversei com ele dizendo que precisava lavar as mãos pra não colocar na boca, que aquilo ali não fazia bem pra saúde, (...), mas continuavam botando apelidos nele aí eu fui trabalhar pela profissão, qual a profissão de mecânico. (Ester. Entrevista narrativa, 2016)

É importante compreendermos de que lugar cada docente se posiciona para construir sua concepção de diferença e apresentar seu entendimento do que seja a diversidade cultural em cada comunidade rural, logo que as questões sobre as identidades trazidas e produzidas pelos indivíduos, que se encontram imersos nos muitos grupos que compõem a comunidade escolar, sempre estiveram em segundo plano, isso quando não eram camufladas através das tentativas de subvertê-las. É nesse contexto que começamos a perceber que, enquanto professores, precisamos nos atentar para os aspectos intrínsecos às diferenças, pois estes são fatores preponderantes para a construção da autonomia e a busca da liberdade. 
A ação de abrir diálogo com a criança, na busca de entendimento das razões de chegar a escola em uma determinada situação, como estar melada por graxa, revela um modo de trabalhar a diferença entendendo-a como um ponto que atravessa a prática educativa que o docente desenvolve na escola, motivo pelo qual adota a prospectiva do diálogo, mas ao mesmo tempo desfoca o real problema sob o pretexto de inserir a discussão sobre profissão, na tentativa de que, abordasse as características de um sujeito que exerce a profissão de mecânico, evitaria por parte dos estudantes o bullying em relação ao menino que chegava melado de graxa.

Acreditamos que, se nos atentarmos aos aspectos intrínsecos às questões da diferença, no Ensino Fundamental em Classes multisseriadas, isso exigirá de nós, como professores, a capacidade de visualizar, para além das condições sociais e econômicas dos indivíduos, notando que seus princípios se constroem a partir das interações culturais entre os sujeitos e de acordo com o modo de vida deles.

Conforme as narrativas de Edson e Clóvis, as diferenças que aparecem em sala de aula têm um maior enfoque nas condições sociais e econômicas.

[...] o professor que está na sala de aula se depara com essas diferenças, a gente encontra filho de pais que não têm aquele acompanhamento como deveria ter com os filhos, principalmente na sala de aula, a gente também encontra filhos que vêm para a escola que não têm assim uma boa alimentação em casa. (Edson, entrevista narrativa, 2016)

[...] a gente percebe que tem crianças que vêm sem ter feito uma alimentação adequada e a gente tenta manusear isso de uma forma diferente, [...] às vezes algum pode chegar atrasado porque a mamãe demorou de passar o café pra ele, muitas vezes a gente percebe que não tinha café em casa, [...]. (Clóvis, entrevista narrativa, 2016)

Considerando tais discussões, salientamos que os sentidos atribuídos ao termo diferença estão relacionados, na maioria das vezes, às desigualdades sociais que o tornam desprovido de seu verdadeiro sentido, provocando uma condição de esvaziamento de sua semântica e significado, como uma forma intencionalmente apresentada para que os sujeitos se lancem na busca de uma afirmação da igualdade, tomando como base o distanciamento da diferença. Não há, portanto, na ótica dos dois docentes, uma perspectiva analítica das diferenças que evidencie as singularidades dos sujeitos, como marca histórica de sua constituição e condição étnica, racial, sexual, entre outras.

Ao marcar as diferenças pelo crivo da desigualdade social, a tentativa que se evidencia nas práticas educativas é de normalização de ações e atitudes, e às vezes de mero entendimento da situação em que cada um vive, sem produzir problematizações e reflexões que promovam a ideia da heterogeneidade das diferenças como marca do pluralismo da diversidade. Esse entendimento ganha notoriedade quando o conhecimento de si do próprio professor o mobiliza 
a pensar para além de uma ação homogeneizadora em relação ao estudante, abrindo espaço para que a escola e as práticas educativas reflitam a pluralidade cultural vivenciada por cada estudante, possibilitando uma discussão de diferença que transcenda o mero reconhecimento das mesmas pelo crivo da desigualdade social.

A ação docente, nesse momento, requer que o professor contemple a realidade do aluno, colocando-se à disposição, numa intenção de permuta e alternância de pontos de vista, em que o professor se coloca no lugar do aluno e vice-versa, pois, somente assim, teremos a construção de uma relação recíproca entre docente e discente. Isso possibilitaria novas condições de compreensão desse sujeito que está composto por dimensões cognitivas, sociais e afetivas.

Assim sendo, reiteramos que o conhecimento de si desencadeou inúmeras perspectivas, deixando como ponto elementar de uma formação docente, pensada e desenvolvida por/entre professores, cinco princípios importantes e necessários de/para uma formação pensada a partir de contextos da diferença na docência rural, a saber: auto/eco/coformação, autonomia, açãoreflexão-formação, diversidade e reciprocidade.

a) Autonomia - elemento que será construído ao longo do processo de formação e atuação docente. Sendo "entendida como qualidade na forma pela qual nos conduzimos, entendida circunstancialmente, a autonomia profissional é uma construção que fala tanto da forma pela qual se atua profissionalmente como dos modos desejáveis de relação social" (Contreras, 2012, p. 216). Este princípio é responsável pela nossa postura e posicionamento, enquanto docentes, pois está envolvida nesta questão a forma como vivemos a subjetividade. A autonomia se processa quando o conhecimento de si nos leva a perceber o valor das ações e situações que o docente desenvolve ao exercer uma prática profissional que emerja dos contextos em que o docente tenha plena inscrição histórica, política e social de suas crenças e valores educativos. Esse é o caminho pelo qual a inventividade e a criatividade passam a ser marcas fundantes das relações com o outro e com o ambiente no processo de produção de atitudes de acolhimento e respeito às diferenças, e, consequentemente, às práticas educativas que se desenvolvem a partir delas.

b) Ação-reflexão-formação - este princípio pode ser representado a partir de um procedimento de retroalimentação, efetivando-se apenas na complementariedade dos procedimentos intrínsecos à ação efetivada na docência. Assim, ele implica a contemplação da realidade profissional em que estamos inseridos, a mobilização que conseguimos fazer sobre o desenvolvimento do nosso trabalho, a articulação com as novas formas de conhecimento e a proposição de uma reorganização dessa ação. Em tese, esse princípio parte da ideia de que o 
docente age, sobre a sua ação reflete, provocando novas tessituras sobre a ação, desencadeando um processo de formação que retroalimenta as futuras ações desenvolvidas. Assim, esse é o princípio de ressignificação constante das práticas educativas e de modos de ser e de viver a docência nas classes multisseriadas. Neste princípio, não cabe a ideia de previsibilidade ou de ações que meramente se repetem, desconsiderando os contextos de vivências e de produção de experiências.

c) Auto/eco/coformação - este princípio compreende uma mobilização instituída a partir da articulação de elementos específicos do movimento de interiorização/exteriorização, em que o ambiente que nos acolhe tem uma força determinante e demanda um conjunto de fatores inerentes aos processos de autorreflexão sobre nossa própria formação, e de corresponsabilidade pela nossa formação.

Aqui, a pesquisa-formação é um elemento fundante e desencadeador das possibilidades que integram este princípio, por promover um espaço de formação construído pela coletividade e pela interação dos professores participantes. Neste espaço, os participantes constroem juntos as propostas da formação, de acordo com suas necessidades, em um jogo de cumplicidade, entendimento e compreensão, em que o processo de reciprocidade acontece e o conhecimento de si ressurge.

Como um modo de formação na escola rural, o conhecimento daí resultante possibilita outros olhares para o fazer docente, com todos os seus sentidos e significados ideológicos e simbólicos construtores de identidades e caracterizados pelas relações estabelecidas entre os sujeitos que aí convivem com os elementos do tempo e da natureza. Dessa forma, o princípio em questão traz em si uma dinamicidade potencializada pela interdependência das dimensões relacionais que o sujeito precisa estabelecer consigo mesmo (autoformação), com seu espaço de vivência e convivência (ecoformação), responsabilizando-se pelo seu processo de formação e de seus pares (coformação), construindo um espaço de negociação e diálogo.

Conforme Pineau (2014), este espaço de formação provoca apropriações de poder que se desdobram de duas maneiras, aquela que acontece quando o indivíduo se torna sujeito de sua própria formação, e a que se dá quando este indivíduo se torna objeto de sua formação, caracterizando o processo de autoformação, que precisa acontecer paralelamente à ecoformação e à coformação, em um movimento tridimensional e interdependente, no decurso da vida.

d) Reciprocidade - tal princípio requer um exercício muito aprofundado do conhecimento de si, sendo um processo que requer a construção de um posicionamento diante do outro. Falar desse outro é estabelecer uma relação a partir de concepções de uma identidade 
que se constrói e se reconstrói nessa interação. Desse modo, as situações vivenciadas no cotidiano escolar podem ser pensadas a partir de concepções sobre a multirreferencialidade, em que a compreensão do indivíduo esteja claramente definida com base na pluridimensionalidade, podendo ainda entender os sujeitos como seres multicausais, que precisam ser compreendidos a partir de uma visão que contemple sua imersão no mundo.

Acreditamos, então, que através da construção da autonomia docente, em consonância com os novos valores, sentidos e significados atribuídos às diversas ruralidades contemporâneas, podemos ampliar as condições de uma nova estrutura educacional, com um enfoque na reinvenção da escola rural. Neste caso, não cabe mais o desenvolvimento de práticas pedagógicas que desconsiderem as condições de vida dos diversos grupos que compõem nossas escolas da roça, mas direcionamentos outros, para a docência, de maneira que seja priorizada uma reconfiguração na forma de pensar a escola, considerando as questões da identidade e diferença na produção das relações interculturais que constituem os espaços rurais.

e) Diversidade - este princípio da formação que apresentamos aqui, vem sendo pensado como um elemento importante a ser considerado como uma das dimensões da profissão docente na contemporaneidade, uma vez que a diversidade precisa estar atrelada, cotidianamente, às concepções e ações de docentes, pois a escola é o espaço frequentado por pessoas com diferentes jeitos de ser e com modos de vida específicos que representam cada grupo e comunidade de origem dessas pessoas, isso significa dizer que é na escola que acontece o encontro de culturas.

É com esse encontro de culturas que surgem os conflitos e possivelmente as negociações a partir de diálogos entre os sujeitos das diferenças que ocupam os espaços da escola. Sendo assim, professores e professoras precisam mediar conflitos e realizar intervenções com caráter formativo que não desconsidere, muito menos, diminua a importância das diferenças de cada sujeito, pois são essas diferenças que compõem o conjunto da diversidade cultural.

A diversidade é tomada aqui como quinto princípio da formação docente em escolas com classes multisseriadas por levar em conta que os espaços de vida em comunidades rurais é permeado por diversos modos de ser, fazer e viver em que os sujeitos tem se afirmado a partir de um lugar de fala que compreende as vozes de meninos e meninas, homens e mulheres atravessados pelos elementos da diversidade e, por isso, durante muito tempo, foram invisibilizados por uma sociedade que concentrava esforços no fortalecimento de grupos hegemônicos prospectando a manutenção da classe dominante. 
Cabe ressaltar que, a diversidade como uma das dimensões da profissão docente é compreendida como uma concepção que agrega valor ao fazer docente por possibilitar espaço para a intermediação de conflitos que surgem nas relações que acontecem no ambiente escolar, objetivando a valorização do sujeito em sua pluridimensionalidade. Uma formação docente que preza pela diversidade como um dos princípios da docência em Classes multisseriadas, lança mão de concepções que deem centralidade aos movimentos instituídos a partir das relações intersubjetivas de cada pessoa que compõem o espaço escolar ou a comunidade rural em que a escola está inserida, valorizando-os como sujeitos da subjetividade e da diferença.

Os cinco princípios da formação docente em Classes multisseriadas se colocam como elementos potencializadores do fazer docente em espaços escolares, que ainda, se encontram permeados por forças padronizadoras, impondo uma ideologia que favorece os sentidos de esvaziamento do real significado da diferença. É importante salientar que tais princípios emergiram no decorrer do desenvolvimento da pesquisa-formação através de reflexões provenientes dos modos como trabalho, em sala de aula, com as diferenças vem sendo desenvolvido, da formação que o professor de Classes multisseriadas tem, das concepções que ele traz a respeito da diferença, de como este enxerga a vida e como a vida o toca. Sendo assim, os cinco princípios carregam consigo possiblidades que propõem aos professores um fazer docente que valorize a maneira de ser de alunos e alunas, buscando a seu modo, intermediar os processos de conflito, tensões e negociações inerentes ao encontro das culturas na escola.

São, portanto, princípios que se fundamentam a partir das subjetividades reveladas nas tessituras das narrativas de cada um, e que, no movimento da pesquisa-formação, nos permite entender como cada professor vivencia e experiencia a docência, em que a reflexão de si, a aprendizagem pelo diálogo com o outro e com o próprio ambiente, constituem modos de desenvolvimento do conhecimento de si e das práticas educativas que cada um desenvolve.

\section{Considerações finais}

O movimento de pesquisa-formação se efetivou na ambivalência que esse próprio estudo nos trouxe, uma vez que fazer a pesquisa constituiu, também, para os autores da mesma possibilidade de conhecimento de si a partir da relação que se efetivou com os colaboradores do estudo, com a própria essência do trabalho com a diferença nas classes multisseriadas, bem como com as próprias reflexões que se produziram aqui como forma de marcar o tom analítico que o texto se processou. Esse é um achado da pesquisa-formação que não poderia deixar de ser aqui, também, registrado. 
As narrativas dos professores da roça foram desencadeando um movimento formativo que qualificou o desenvolvimento do processo da pesquisa-formação, como um momento que favoreceu o acontecimento da autoformação, da heteroformação e da ecoformação. Neste sentido, o conhecimento de si foi sendo colocado como possibilidade que propicia outros espaços de formação na escola rural, por apresentar as condições de reflexividade sobre os pontos que cada um considerou (ou considera importantes) em seu percurso de vida-formaçãoprofissão. Assim, as trajetórias de vida, de escolarização foram fundantes para entendermos como cada sujeito vive e desenvolve saberes sobre a escola multisseriada, sobre as práticas educativas e sobre seus modos próprios de ser e de viver a docência.

O conhecimento de si é posto de maneira a ser considerado como outro espaço de formação na escola rural por nos direcionar a caminhos que poderão orientar a construção de uma proposta educacional que leve em conta as condições de existência de cada sujeito, entendendo que seu jeito de ser/fazer/viver envolve a multidimensionalidade responsável por suas condições no presente e perspectivas de futuro, que são revistas e repensadas como elementos de sua exterioridade enquanto ser-sujeito. Esse outro espaço, portanto, é o espaço do próprio sujeito na sua constituição identitária, em que a autonomia, a reflexão e a ação demarcam as formas de criar e de produzir a docência nos contextos da singularidade de uma escola multisseriada.

Neste sentido, no desenvolvimento da pesquisa-formação, se colocava, como evidência constante, a ausência de conhecimento e a compreensão do sentido da identidade e da diferença, por parte dos professores-colaboradores da pesquisa, por não terem, ao longo da profissão, momentos específicos destinados a discussões e/ou formações que tratassem desta temática, de maneira aprofundada. Assim, quando se discutiam temas relacionados à diversidade, tinha-se como base o material de orientação didática, que sempre permeou os espaços educacionais e que, por sua vez, esvaziava os verdadeiros sentidos da diferença.

A diferença aparece na pesquisa com variados sentidos, ora como característica própria de cada sujeito, ora como um elemento que precisa ser mascarado, a partir das tentativas de homogeneizar os alunos.

Os princípios formativos emergiram do conhecimento de si, revelando como cada sujeito produziu a autonomia profissional, entendida como condição de inventividade e de criatividade no trato com as práticas que desenvolvem no ambiente escolar. Disso, advém a ideia de que as produções de si surgem de ação-reflexão-formação que os professores efetivam ao serem sujeitos que aprendem com o outro, consigo mesmo e com o ambiente, caracterizando 
o princípio da auto, hetero e ecoformação. Assim, a reciprocidade é transversal nas práticas educativas e formativas dos professores, pois é na relação com o outro, sobretudo com o estudante que as tessituras do fazer docente se ressignificam e fundamentam uma percepção de diversidade, ainda que homogeneizadora das diferenças percebidas pelo ofício da docência.

\section{Referências}

AMIGUINHO, A. J. M. Escola em meio rural: uma escola portadora de futuro? Revista Educação, Santa Maria, v. 33, n. 1, p. 11-32, jan./abr. 2008.

ANDRÉ, Marli. Pesquisa, formação e prática docente. In. ANDRÉ, Marli. (Org). O papel da pesquisa na formação e prática dos professores. 2. ed. Campinas: Papirus, 2002. p. 55-70

CARNEIRO, Maria José. Ruralidades: novas identidades em construção. Estudos Sociedade e Agricultura, n. 11, p. 53-75, out. 1998.

CONTRERAS, José. A autonomia de professores. 2. ed. São Paulo: Cortez, 2012.

DELORY-MOMBERGER, Christine. Formação e socialização: os ateliês biográficos de projeto. Educação e Pesquisa, São Paulo, v. 32, n. 2, p. 359-371, mai./ago. 2006.

DOMINICÉ, Pierre. O processo de formação e alguns dos seus componentes relacionais. In: FINGER, M.; NÓVOA, A. (Orgs.). O método (auto)biográfico e a formação. 2. ed. Natal: EDUFRN, 2014. p. 77-90.

JOSSO, Marie-Christine. As narrações centradas sobre a formação durante a vida como desvelamento das formas e sentidos múltiplos de uma existencialidade singular-plural. Revista da FAEEBA: Educação e Contemporaneidade, Salvador, v. 17, n. 29, p. 17-30, jan./jun., 2008.

JOSSO, Marie-Christine. Caminhar para si. Porto Alegre: EDIPUCRS, 2010.

PINEAU, Gaston. A autoformação no decurso da vida: entre a hetero e a autoformação. In: FINGER, M. NÓVOA, A. (Org.). O método (auto)biográfico e a formação. 2. ed. Natal: EDUFRN, 2014. p. 91-110.

PINEAU, Gaston; LE GRAND, Jean-Louis. As histórias de vida. Natal: EDUFRN, 2012.

SOUZA. Pesquisa narrativa e escrita (auto)biográfica: interfaces metodológicas e formativas. In: SOUZA, Elizeu Clementino; ABRAHÃO, Maria Helena Menna Barreto. (Orgs.). Tempos, narrativas e ficções: a invenção de si. Porto Alegre: EDIPUCRS; Salvador: EDUNEB, 2006. p. 135-148. 